\title{
Prevalence of Resistance Genes to Biocides in Antibiotic-Resistant Pseudomonas Aeruginosa Clinical Isolates
}

\section{Farzad Khademi ( $\nabla$ k_farzad@yahoo.com )}

Ardabil University of Medical Sciences: Ardebil University of Medical Sciences https://orcid.org/0000-0001-6181-4903

Shahram Habibzadeh

Ardabil University of Medical Sciences: Ardebil University of Medical Sciences

Hamid Vaez

Zabol University of Medical Sciences

Mohsen Arzanlou

Ardabil University of Medical Sciences: Ardebil University of Medical Sciences

Somayeh Safarirad

Ardabil University of Medical Sciences: Ardebil University of Medical Sciences

Seyed Ali Bazghandi

Ardabil University of Medical Sciences: Ardebil University of Medical Sciences

Amirhossein Sahebkar

Mashhad University of Medical Sciences

\section{Research Article}

Keywords: Pseudomonas aeruginosa, resistance, triclosan, benzalkonium chloride, chlorhexidine digluconate, formaldehyde

Posted Date: September 20th, 2021

DOI: https://doi.org/10.21203/rs.3.rs-886208/v1

License: (1) This work is licensed under a Creative Commons Attribution 4.0 International License. Read Full License 


\section{Abstract}

Background: Biocides are frequently used as preservative, disinfectant and sterilizer against many microorganisms in hospitals, industry and home. However, the resistance rate of Pseudomonas aeruginosa ( $P$. aeruginosa) strains to biocides is increasing. The aim of this study was to evaluate the antimicrobial activity of four frequently used biocides against $P$. aeruginosa and to determine the prevalence of genes involved in biocide resistance.

Methods: A total of 76 clinical isolates of $P$. aeruginosa strains were used in the present study. The minimum inhibitory concentrations (MICs) of four biocides, i.e. chlorhexidine digluconate, benzalkonium chloride, triclosan and formaldehyde, against $P$. aeruginosa strains were determined using agar dilution method. In addition, the prevalence of biocide resistance genes was determined using the polymerase chain reaction (PCR) method.

Results: In the present study, the highest $\mathrm{MIC}_{90}$ value was observed for benzalkonium chloride $\left(\mathrm{MIC}_{90}=1024 \mu \mathrm{g} / \mathrm{mL}\right)$, followed by formaldehyde $\left(\mathrm{MIC}_{90}=512 \mu \mathrm{g} / \mathrm{mL}\right)$, triclosan $\left(\mathrm{MIC}_{90}=512 \mu \mathrm{g} / \mathrm{mL}\right)$ and chlorhexidine digluconate $\left(\mathrm{MIC}_{90}=64 \mu \mathrm{g} / \mathrm{mL}\right)$. Furthermore, the prevalence of qacE $\triangle 1$, qacE, qacG, fabV, cepA and fab/ genes were $73.7 \%(n=56), 26.3 \%(n=20), 11.8 \%(n=9), 84.2 \%(n=64), 81.5 \%$ $(n=62)$ and $0 \%(n=0)$, respectively. A significant association was observed between the presence of biocide resistance genes and MICs $(p<0.05)$. Furthermore, there was no significant association between the presence of biocide resistance genes and antibiotic resistance $(p>0.05)$, except for levofloxacin and norfloxacin antibiotics and $q a c E$ and $q a c G$ genes $(p<0.05)$.

Conclusion: Our results revealed that chlorhexidine digluconate is the most effective biocide against $P$. aeruginosa isolates in Ardabil hospitals. However, we recommend continuous monitoring of the antimicrobial activity of biocides and the prevalence of biocideassociated resistance genes for a better prevention of microorganism dissemination and infection control in hospitals.

\section{Introduction}

Pseudomonas aeruginosa ( $P$. aeruginosa) is a Gram-negative bacillus, which is frequently isolated from hospital environments, especially from medical equipments used in intensive care units (ICUs) [1-3]. P. aeruginosa is an opportunistic human pathogen that is associated with various community-acquired and nosocomial infections such as ventilator-associated pulmonary infections, skin and soft-tissue infections, catheter-related urinary tract infections, eye and ear infections, bloodstream infections, endocarditis and surgical site/transplantation infections [1-3]. Therefore, it seems that hygiene control of surfaces and medical equipments in the hospital settings in terms of $P$. aeruginosa contamination is important because nosocomial infections are considered as a growing global threat in terms of economical and public health [3]. The most common antiseptic and disinfectant biocides used in clinical settings are chlorhexidine digluconate (a biguanide), benzalkonium chloride (a quaternary ammonium compound), triclosan (a bisphenol) and formaldehyde (an aldehyde) [4,5]. However, several studies have reported bacterial resistance to various biocides due to the presence of resistance genes. On the other hand, the risk of $P$. aeruginosa infections in ICU-hospitalized patients is high (up to $30 \%$ ) despite applying hygiene programs [5]. Such a high prevalence can be attributed to the resistance of $P$. aeruginosa strains against a variety of antiseptics and disinfectants over time [6]. Another problem is the emergence of multi-drug resistant (MDR) $P$. aeruginosa strains, which can lead to treatment failure [3]. Interestingly, P. aeruginosa strains have shown cross-resistance to biocides and antibiotics with probably similar mechanisms, thereby making bacterial elimination from hospital environments difficult $[5,7]$. Therefore, obtaining information on the prevalence and mechanisms of bacterial resistance to antimicrobial agents and the selection of suitable biocides and antibiotics can be helpful for controlling hospital-acquired infections caused by $P$. aeruginosa. Several mechanisms of resistance to antibiotics and tolerance to biocides have been identified in $P$. aeruginosa strains including: 1) simple growth requirements and ability of biofilm formation, 2) enzymatic degradation, 3) target site modification, 4) outer membrane impermeability, and 5) presence of efflux pumps. These properties are involved in bacterial persistence in medical environments and development of nosocomial infections [2, 8-13].

Various compounds are used in hospitals and non-hospital environments in Ardabil city but there is no exact data on the rate of biocide effectiveness against local isolates of $P$. aeruginosa. Moreover, the mechanisms of biocide resistance in $P$. aeruginosa clinical isolates of Ardabil are still unclear. Therefore, the aim of the current study was to assess the distribution of biocide resistance genes, namely qacE $\triangle 1$, qacE, qacG, fabV, cepA and fabl, and to determine the minimum inhibitory concentrations (MICs) of various biocides against antibiotic-resistant $P$. aeruginosa strains isolated from clinical samples in Ardabil.

\section{Methods}

\subsection{Data on $P$. aeruginosa isolates}


A total of 76 confirmed clinical $P$. aeruginosa isolates were obtained from various specimens in Ardabil hospitals and then used to assess the distribution of biocide resistance genes as well as determination of the MICs of four biocides. Drug resistance characteristics of $P$. aeruginosa isolates was evaluated using the disk diffusion method based on the Clinical and Laboratory Standards Institute (CLSI, 2018) guideline [14]. Data on the prevalence of class I integron, harboring resistance genes to biocides and antibiotics, was used in this study in order to evaluate the association with resistance to biocides. It is noteworthy, the prevalence of antibiotic resistance along with class I integrin rate were previously determined by authors $[15$, unpublished data].

\subsection{Preparation of biocide solutions}

Biocides used in this study were chlorhexidine digluconate (20\%) (Sigma-Aldrich, USA), benzalkonium chloride (>95\%) (Sigma-Aldrich, USA), triclosan (98\%) (Bio Basic, Canada) and formaldehyde (37\%) (Thermo Fisher Scientific, USA). Stock solutions of antimicrobial agents were prepared in distilled water or water-alcohol for water-insoluble antimicrobial agents. All antibacterial solutions were sterilized using sterile syringe filters $(0.22 \mu \mathrm{m})$ before use.

\subsection{Determination of the MICs of biocides}

The MICs of antiseptics and disinfectants including chlorhexidine digluconate, benzalkonium chloride, triclosan and formaldehyde were determined by agar dilution technique and according to the CLSI guideline [14]. For this purpose, at first a range of biocide concentrations $(0.125-1024 \mu \mathrm{g} / \mathrm{mL})$ was prepared in Mueller-Hinton agar medium and then a $0.5 \mathrm{McF}$ arland standard concentration of $P$. aeruginosa isolates $\left(1.5 \times 10^{8} \mathrm{cfu} / \mathrm{mL}\right)$ was prepared in normal saline. Finally, diluted bacterial inoculum $(1: 10)\left(1.5 \times 10^{7} \mathrm{cfu} / \mathrm{mL}\right)$ was poured onto medium containing different biocides as a spot $\left(10^{4} \mathrm{cfu}\right.$ per spot). The plates were incubated at $37^{\circ} \mathrm{C}$ overnight and then checked in terms of bacterial growth. In the current study, epidemiological cut-off value (ECOFF) for antibacterial susceptibility testing against four biocides was determined equal to $\mathrm{MIC}_{95}(95 \%$ rule). Therefore, $P$. aeruginosa strains with higher MIC value compared with ECOFF value were considered as resistant organisms.

\subsection{Detection of biocide resistance genes}

Extraction of total genomic DNA was done using a simple boiling method. Extracted DNA was stored at $-20{ }^{\circ} \mathrm{C}$ until use for detection of biocide resistance genes. The presence of $q a c E \triangle 1$, qacE, qacG, fabV, cepA and fab/genes was detected by specific primers in polymerase chain reaction (PCR). According to the thermal cycling condition for amplification and the oligonucleotide primer sequences presented in Table 1, PCR was performed in a volume of $25 \mu \mathrm{L}$ containing $20 \mu \mathrm{L}$ of master mix (Ampliqon, Denmark), $1 \mu \mathrm{L}$ of each primers $(10 \mu \mathrm{mol} / \mathrm{L})$ and $3 \mu \mathrm{L}$ of extracted DNA. PCR products were detected by electrophoresis on $1 \%$ agarose gel in a TBE $0.5 x$ buffer and then confirmed by sequencing technique.

Table 1. Used primers and PCR programs in the present study 


\begin{tabular}{|c|c|c|c|c|c|c|c|c|}
\hline \multirow[t]{2}{*}{ Gene } & \multirow[t]{2}{*}{ Primer sequence } & \multicolumn{5}{|c|}{ Thermal cycling condition } & \multirow[t]{2}{*}{ Amplicon size (bp) } & \multirow[t]{2}{*}{ Reference } \\
\hline & & 1 & 2 & 3 & 4 & Cycle & & \\
\hline \multirow[t]{2}{*}{ qacE $\Delta 1$} & F: AATCCATCCCTGTCGGTGTT & 94 & 94 & 53 & 72 & \multirow[t]{2}{*}{30} & \multirow[t]{2}{*}{190} & \multirow[t]{2}{*}{16} \\
\hline & R: CGCAGCGACTTCCACGATGGGGAT & $\begin{array}{l}4 \\
\min \end{array}$ & $1 \mathrm{~min}$ & $50 \mathrm{sec}$ & $1 \mathrm{~min}$ & & & \\
\hline \multirow[t]{2}{*}{ qacE } & F: TTAGGATGGAGACGAAATTTTCA & 94 & 94 & 59 & 72 & \multirow[t]{2}{*}{30} & \multirow[t]{2}{*}{240} & \multirow[t]{2}{*}{ This study } \\
\hline & $\begin{array}{l}\text { R: } \\
\text { CGCTTAACACCTAGTATTATTACCGT }\end{array}$ & $4 \min$ & $1 \mathrm{~min}$ & $1 \mathrm{~min}$ & $1 \mathrm{~min}$ & & & \\
\hline \multirow[t]{2}{*}{ fabl } & F: ATGCTGAAAATTGTTTTGAGTGAGA & 94 & 94 & 59 & 72 & \multirow[t]{2}{*}{30} & \multirow[t]{2}{*}{830} & \multirow[t]{2}{*}{ This study } \\
\hline & R: TTCATCATCCTTCATAGATTGGCTC & $4 \min$ & $1 \mathrm{~min}$ & $1 \mathrm{~min}$ & $1 \mathrm{~min}$ & & & \\
\hline \multirow[t]{2}{*}{$q a c G$} & F: TTGAATAATTGGTTATTTCTGGCT & 94 & 94 & 59 & 72 & \multirow[t]{2}{*}{30} & \multirow[t]{2}{*}{333} & \multirow[t]{2}{*}{ This study } \\
\hline & R: TTAGTGAACACTTGCCTTAGATAG & $4 \mathrm{~min}$ & $1 \mathrm{~min}$ & $1 \mathrm{~min}$ & $1 \mathrm{~min}$ & & & \\
\hline \multirow[t]{2}{*}{ cepA } & F: GCTCGCTGATGTCGGTAGG & 94 & 94 & 59 & 72 & \multirow[t]{2}{*}{30} & \multirow[t]{2}{*}{481} & \multirow[t]{2}{*}{ This study } \\
\hline & R: CTGCTGGCAGTGCACTATTC & $4 \min$ & $1 \mathrm{~min}$ & $1 \mathrm{~min}$ & $1 \mathrm{~min}$ & & & \\
\hline \multirow[t]{2}{*}{$f a b V$} & F: TCGACCTGGTGGTCTACAGC & 94 & 94 & 59 & 72 & \multirow[t]{2}{*}{30} & \multirow[t]{2}{*}{530} & \multirow[t]{2}{*}{ This study } \\
\hline & R: GACCTGCTCGATGCAACC & $4 \mathrm{~min}$ & $1 \mathrm{~min}$ & $1 \mathrm{~min}$ & $1 \mathrm{~min}$ & & & \\
\hline
\end{tabular}

Abbreviations: 1-Initial denaturation, 2-Denaturation, 3-Annealing, 4-Extension.

\subsection{Data analysis}

All data on the MICs of biocides against $P$. aeruginosa strains, the presence of resistance genes to biocides and $P$. aeruginosa resistance to various antibiotics were collected and their correlation analyzed by the SPSS software version 16 . The Chi-square test was used to analyses and a $p$ value of $<0.05$ was considered statistically significant.

\section{Results}

In the present study, among $76 P$. aeruginosa clinical isolates, the prevalence of qacE 1 , qacE, qacG, fabV, cepA and fab/genes were 73.7\% $(n=56), 26.3 \%(n=20), 11.8 \%(n=9), 84.2 \%(n=64), 81.5 \%(n=62)$ and $0 \%$, respectively. As shown in Table 2, the MIC range for various biocides was as follows: benzalkonium chloride 256-1024 $\mu \mathrm{g} / \mathrm{mL}$, formaldehyde 32-512 $\mu \mathrm{g} / \mathrm{mL}$, triclosan 32-512 $\mu \mathrm{g} / \mathrm{mL}$ and chlorhexidine digluconate 4-64 $\mu \mathrm{g} / \mathrm{mL}$. In total, the highest $\mathrm{MIC}_{90}$ was observed for benzalkonium chloride $\left(\mathrm{MIC}_{90}=1024 \mu \mathrm{g} / \mathrm{mL}\right)$, followed by formaldehyde $\left(\mathrm{MIC}_{90}=512 \mu \mathrm{g} / \mathrm{mL}\right)$, triclosan $\left(\mathrm{MIC}_{90}=512 \mu \mathrm{g} / \mathrm{mL}\right)$ and chlorhexidine digluconate $\left(\mathrm{MIC}_{90}=64 \mu \mathrm{g} / \mathrm{mL}\right)$, Therefore, it seems that chlorhexidine digluconate and benzalkonium chloride had the highest and the lowest effects, respectively, in terms of growth inhibition of $P$. aeruginosa isolates in this study. As shown in Table 3, a significant association was observed between the presence of biocide resistance genes and MICs $(p<0.05)$. Additionally, biocide resistance gene profiles revealed that isolates simultaneously harboring qacE $\triangle 1$, cepA and fabV genes are more prevalent $(\mathrm{n}=35,46 \%)$, while 8 isolates $(10.5 \%)$ did not harbor any biocide resistance genes (Table 4). Moreover, strains containing biocide resistance genes had higher $\mathrm{MIC}_{50}$ and $\mathrm{MIC}_{90}$ values compared with isolates without these genes. In this study, ECOFF for resistance to benzalkonium chloride, triclosan, formaldehyde and chlorhexidine digluconate were determined as 1024, 512, 512 and $64 \mu \mathrm{g} / \mathrm{mL}$, respectively.

Isolates with and without biocide resistance genes were compared in terms of resistance rate to the following antibiotics: piperacillin, piperacillin-tazobactam, ticarcillin-clavulanate, ceftazidime, cefepime, aztreonam, doripenem, imipenem, meropenem, gentamicin, tobramycin, amikacin, netilmicin, ciprofloxacin, levofloxacin, norfloxacin, lomefloxacin and ofloxacin. There was no significant association between the presence of biocide resistance genes and antibiotic resistance $(p>0.05)$, except for levofloxacin and norfloxacin antibiotics and $q a c E$ and $q a c G$ genes $(p<0.05)$. The prevalence of integron I positive $P$. aeruginosa strains harboring qacE $\triangle 1$ gene was 32 out of 76 (42.1\%). No significant association was observed between the presence of class I integron and biocide resistance genes ( $q a c E \Delta 1, q a c E$, cepA and fabV), except for qacG gene $(p=0.00)$.

Table 2. Minimal inhibitory concentration of biocides against clinical isolates of $P$. aeruginosa 


\begin{tabular}{|c|c|c|c|c|c|c|c|c|c|c|c|}
\hline \multirow[t]{2}{*}{ Biocides } & \multicolumn{10}{|c|}{$\mathrm{MIC}(\mu \mathrm{g} / \mathrm{mL})$} & \multirow{2}{*}{$\begin{array}{l}\text { ECOFF }^{*} \\
(\mu \mathrm{g} / \mathrm{mL})\end{array}$} \\
\hline & 4 & 16 & 32 & 64 & 128 & 256 & 512 & 1024 & $\mathrm{MIC}_{50}$ & $\mathrm{MIC}_{90}$ & \\
\hline \multirow[t]{2}{*}{ Formaldehyde } & - & - & 2 & 47 & 15 & - & 12 & - & 64 & 512 & 512 \\
\hline & & & $(2.6 \%)$ & $(61.9 \%)$ & $(19.7 \%)$ & & $(15.8 \%)$ & & & & \\
\hline \multirow{2}{*}{$\begin{array}{l}\text { Benzalkonium } \\
\text { chloride }\end{array}$} & - & - & - & - & - & 12 & 53 & 11 & 512 & 1024 & 1024 \\
\hline & & & & & & $(15.8 \%)$ & $(69.7 \%)$ & $(14.5 \%)$ & & & \\
\hline \multirow[t]{2}{*}{ Triclosan } & - & - & 11 & 3 & 5 & - & 57 & - & 512 & 512 & 512 \\
\hline & & & $(14.5 \%)$ & (3.9\%) & $(6.6 \%)$ & & $(75 \%)$ & & & & \\
\hline \multirow{2}{*}{$\begin{array}{l}\text { Chlorhexidine } \\
\text { digluconate }\end{array}$} & 4 & 10 & 22 & 40 & - & - & - & - & 64 & 64 & 64 \\
\hline & $(5.3 \%)$ & $(13.2 \%)$ & $(28.9 \%)$ & $(52.6 \%)$ & & & & & & & \\
\hline
\end{tabular}

*ECOFF-epidemiological cut-off value

Table 3. Association between biocide resistance genes and MIC

\begin{tabular}{|c|c|c|c|c|c|c|c|c|}
\hline \multirow[t]{2}{*}{ Biocide (MIC) } & \multicolumn{2}{|c|}{ Formaldehyde } & \multicolumn{2}{|c|}{ Benzalkonium chloride } & \multicolumn{2}{|c|}{ Triclosan } & \multicolumn{2}{|c|}{ Chlorhexidine } \\
\hline & $\leq 128$ & $256 \leq$ & $\leq 256$ & $512 \leq$ & $\leq 128$ & $256 \leq$ & $\leq 16$ & $32 \leq$ \\
\hline qacE $\triangle 1+$ & 46 & 10 & 3 & 53 & 5 & 51 & 6 & 50 \\
\hline qacE $\triangle 1-$ & 18 & 2 & 9 & 11 & 13 & 7 & 8 & 12 \\
\hline p value & 0.019 & & 0.00 & & 0.00 & & 0.02 & \\
\hline qacE+ & 15 & 6 & 2 & 19 & 2 & 19 & 2 & 19 \\
\hline qacE- & 49 & 6 & 10 & 45 & 16 & 39 & 12 & 43 \\
\hline$p$ value & 0.24 & & 0.00 & & 0.426 & & 0.491 & \\
\hline qacG+ & 7 & 2 & 0 & 9 & 0 & 9 & 0 & 9 \\
\hline qacG- & 57 & 10 & 12 & 55 & 18 & 49 & 14 & 53 \\
\hline$p$ value & 0.88 & & 0.00 & & 0.53 & & 0.32 & \\
\hline cepAt & 50 & 12 & 7 & 55 & 8 & 54 & 9 & 53 \\
\hline серA- & 14 & 0 & 5 & 9 & 10 & 4 & 5 & 9 \\
\hline$p$ value & 0.00 & & 0.03 & & 0.00 & & 0.00 & \\
\hline$f a b V+$ & 52 & 12 & 7 & 57 & 8 & 56 & 10 & 54 \\
\hline$f a b V-$ & 12 & 0 & 5 & 7 & 10 & 2 & 4 & 8 \\
\hline$p$ value & 0.00 & & 0.01 & & 0.00 & & 0.00 & \\
\hline
\end{tabular}

Table 4. Gene profile and minimal inhibitory concentration of biocides 


\begin{tabular}{|c|c|c|c|c|c|c|c|c|c|}
\hline \multirow[t]{2}{*}{ Gene } & \multirow{2}{*}{$\begin{array}{l}\text { Isolate } \\
\text { (n) }\end{array}$} & \multicolumn{2}{|c|}{$\begin{array}{l}\text { Chlorhexidine } \\
\text { digluconate }\end{array}$} & \multicolumn{2}{|c|}{ Triclosan } & \multicolumn{2}{|c|}{$\begin{array}{l}\text { Benzalkonium } \\
\text { chloride }\end{array}$} & \multicolumn{2}{|c|}{ Formaldehyde } \\
\hline & & $\mathrm{MIC}_{50}$ & $\mathrm{MIC}_{90}$ & $\mathrm{MIC}_{50}$ & $\mathrm{MIC}_{90}$ & $\mathrm{MIC}_{50}$ & $\mathrm{MIC}_{90}$ & $\mathrm{MIC}_{50}$ & $\mathrm{MIC}_{90}$ \\
\hline qacE $\Delta 1$ & 2 & 32 & 32 & 0.5 & 64 & 256 & 512 & 64 & 128 \\
\hline qacE & 1 & 32 & 32 & 512 & 512 & 512 & 512 & 64 & 64 \\
\hline qacE $\Delta 1+c e p A$ & 1 & 64 & 64 & 512 & 512 & 512 & 512 & 64 & 64 \\
\hline$q a c E \Delta 1+f a b V$ & 2 & 32 & 64 & 512 & 512 & 512 & 512 & 128 & 128 \\
\hline cepA+fabV & 5 & 32 & 64 & 128 & 512 & 256 & 512 & 64 & 64 \\
\hline$q a c E+c e p A+f a b V$ & 6 & 32 & 64 & 512 & 512 & 512 & 1024 & 128 & 512 \\
\hline$q a c E \Delta 1+c e p A+f a b V$ & 35 & 64 & 64 & 512 & 512 & 512 & 512 & 64 & 512 \\
\hline$q a c E \Delta 1+q a c E+c e p A+f a b V$ & 7 & 64 & 64 & 512 & 512 & 512 & 1024 & 64 & 512 \\
\hline$q a c E \Delta 1+q a c G+c e p A+f a b V$ & 2 & 64 & 64 & 512 & 512 & 512 & 1024 & 64 & 64 \\
\hline$q a c E \Delta 1+q a c E+q a c G+c e p A+f a b V$ & 7 & 64 & 64 & 512 & 512 & 1024 & 1024 & 128 & 512 \\
\hline No gene & 8 & 4 & 64 & 0.5 & 64 & 256 & 512 & 64 & 64 \\
\hline
\end{tabular}

\section{Discussion}

Biocides are basic compounds to control microorganism dissemination and ensuing infections and are frequently used as preservative, disinfectant and sterilizer against various microorganisms, in particular $P$. aeruginosa [17]. One of the most useful biocides against microbes, especially Gram-positive bacteria, is triclosan, which is widely used in toothpastes, soaps and other daily products [17]. Triclosan is an anionic and lipophilic compound, which its anti-bacterial function stems from inhibition of enoyl-acyl-carrier protein reductase (ENR), an enzyme involved in fatty acid synthesis $[19,21]$. However, $P$. aeruginosa strains are inherently resistant to this biocide ( $\mathrm{MIC}>2,000 \mu \mathrm{g} / \mathrm{mL}$ ) [21]. ENR enzymes show diversity among different bacteria in terms of sequence and structure, and contain four isozymes including Fabl (triclosan- sensitive ENR), FabL, FabV and FabK (triclosan-resistant ENRs) [19, 21]. The FabV isozyme is involved in swimming motility, energy metabolism, protein secretion and adherence, and is responsible for $P$. aeruginosa resistance to triclosan biocide [21]. Genes encoding Fabl and FabV enzymes are found in most bacterial chromosomes such as $P$. aeruginosa [19, 21]. Bacterial resistance to triclosan is associated with mutation in the active site of fab/gene and the presence of fabV gene [17, 21]. In the current study, the prevalence $f a b /$ resistance gene among $P$. aeruginosa isolates was $0 \%$. Unlike $f a b /$ gene, the frequency of fabV gene was high in the present study (84.2\%). Zhu et al. showed that deletion of fabV gene confers extremely high susceptibility to triclosan (>2,000 folds) in P. aeruginosa isolates [19]. Similar result was reported by Huang et al. [21]. In this study, the $\mathrm{MIC}_{50}$ and $\mathrm{MIC}_{90}$ values of triclosan for fabV resistance gene- harboring $P$. aeruginosa strains was higher than fabV gene-negative strains (Table 4).

Chlorhexidine digluconate, an antiseptic, disinfectant and preservative, is a bactericidal biocide, which has higher antibacterial activity against Gram-positive compared with Gram-negative bacteria [22]. This biocide is used in oral health antiseptics, hand washes and other hygienic solutions. The antibacterial mechanism of chlorhexidine digluconate is via the bacterial cell membrane [17]. However, $P$. aeruginosa is intrinsically resistant to this biocide due to the presence of an outer membrane [22]. Adaptive resistance to chlorhexidine biocide is mediated by a membrane protein encoded by Acinetobacter chlorhexidine efflux gene (acel). The Acel protein identified in Acinetobacter baumannii is involved in chlorhexidine efflux via an energy-dependent mechanism [23]. However, genes encoding this protein were not identified in $P$. aeruginosa strains in the current study (data not shown). The antiseptic resistance gene cepA, an efflux pump gene, is associated with chlorhexidine resistance in Gram-negative bacteria causing high chlorhexidine MICs [24, 25]. In our study, 62 (81.5\%) cepA-positive strains were found, which is higher than those reported by Mendes et al. (44.5\%) and Vijayakumar et al. (63.6\%) $[24,25]$. According to MIC results, chlorhexidine digluconate is more effective than other biocides against $P$. aeruginosa isolates (MIC range $=4-64 \mu \mathrm{g} / \mathrm{mL}$ ) (Table 2). In this study, the presence of cepA gene had variable effects on the $\mathrm{MIC}_{50}$ and $\mathrm{MIC}_{90}$ values of chlorhexidine (Table 4). 
A major biocide resistance mechanism in Gram-negative bacteria including $P$. aeruginosa is the action of efflux pumps such as the small multidrug resistance family (SMR) $[13,18]$. Biocide resistance genes qacE $\Delta 1$, qacE and qacG encode multidrug efflux pumps, which confer resistance to quaternary ammonium compounds like benzalkonium chloride [13, 18]. In our study, the qacE 1 gene was observed in $73.7 \%$ of clinical isolates of $P$. aeruginosa, while in studies conducted by Subedi et al., Roma $\sim$ et al., Kücken et al., Helal et al. and Mahzounieh et al. the qacE 1 gene was detected in $46.1 \%, 48 \%, 10 \%, 48 \%$ and $91.5 \%$ of the isolates, respectively [13, 18, 26-28]. According to the reports of Subedi et al., Kücken et al., Helal et al. and Mahzounieh et al., 100\%, 2.7\%, 13.5\% and $50 \%$ of $P$. aeruginosa strains, respectively, had the qacE gene [13,26-28], while we detected this gene in $26.3 \%$ of isolates. The frequency of qacG gene in the present study was $11.8 \%$, which is higher compared to the frequency reported by Subedi et al. (0\%) [13]. The $\mathrm{MIC}_{50}$ and $\mathrm{MIC}_{90}$ values of benzalkonium chloride were significantly high for qacE 1 -, qacE- and qacG-positive $P$. aeruginosa strains compared with the negative strains (Table 4).

Class I integron carries qacE $\triangle 1$ and antibiotic resistance genes in clinical isolates of $P$. aeruginosa [13]. Therefore, $P$. aeruginosa strains harboring class I integron are resistant to benzalkonium chloride and various antibiotics [26]. Comparison of our current and previous study (unpublished data) showed that the frequency of integron I-positive $P$. aeruginosa strains harboring qacE $\Delta 1$ gene was 32 out of $76(42.1 \%)$. No significant association was observed between the presence of class I integron and biocide resistance genes (qacE 1 , qacE, cepA and fabV), except for qacG gene $(p=0.00)$.

Formaldehyde is an organic electrophilic biocide, which its mechanism of action involves cross-linking of macromolecules (proteins, RNA and DNA) [17, 29]. Our results indicated that the $\mathrm{MIC}_{50}$ and $\mathrm{MIC}_{90}$ values of formaldehyde were high for biocide resistance genespositive $P$. aeruginosa strains compared with the negative strains (Table 4).

A study by Chuanchuen et al. showed a cross-resistance between biocide and antibiotic resistance. They demonstrated a link between $P$. aeruginosa exposure to triclosan biocide and efflux-mediated resistance to ciprofloxacin [12]. In the present study, there was no significant association between biocide resistance genes and antibiotic resistance, except for levofloxacin and norfloxacin antibiotics and $q a c E$ and $q a c G$ genes. However, more studies are needed to substantiate the existence of biocide-antibiotic cross-resistance.

\section{Conclusion}

Our results revealed that the frequency of resistance genes to benzalkonium chloride, chlorhexidine digluconate, triclosan and formaldehyde was high in clinical isolates of $P$. aeruginosa. Furthermore, $P$. aeruginosa isolates harboring resistance genes had higher MIC values compared with those lacking these genes. On the other hand, chlorhexidine digluconate was the most effective biocide against $P$. aeruginosa isolates in Ardabil hospitals. We recommend continuous monitoring of the antimicrobial activity of biocides and biocide-associated resistance genes in order to prevent microorganism dissemination and infection control in hospitals.

\section{Abbreviations}

MIC: Minimum inhibitory concentration; PCR: Polymerase chain reaction; Pseudomonas aeruginosa: P. aeruginosa; ICU: Intensive care unit; MDR: Multi-drug resistant; CLSI: Clinical and Laboratory Standards Institute; ECOFF: Epidemiological cut-off value; ENR: Enoyl-acylcarrier protein reductase.

\section{Declarations}

\section{Ethics approval and consent to participate}

This research was approved by the Research Ethics Committee of Ardabil University of Medical Sciences (approval ID: IR.ARUMS.REC.1398.591). Informed written consent was given to subjects from whom the samples were obtained for this study.

\section{Consent for publication}

Not applicable.

\section{Availability of data and materials}

The data that support the findings of this study are available from the corresponding author on reasonable request. 


\section{Competing interests}

The authors declare that there is no conflict of interest.

\section{Authors' contributions}

MN, SS and SAB collected the data. FK and HV analyzed the data and led the writing of the manuscript. SH and MA revised the manuscript.

\section{Funding}

This research was supported by Ardabil University of Medical Sciences, Iran (grant number: 1005761).

\section{Acknowledgements}

The authors would like to acknowledge the Vice Chancellor for Research and Technology, Ardabil University of Medical Sciences, Ardabil, Iran, due to financial support.

\section{References}

1. Driscoll JA, Brody SL, Kollef MH (2007) The epidemiology, pathogenesis and treatment of Pseudomonas aeruginosa infections. Drugs 67(3):351-368

2. Vaez H, Salehi-Abargouei A, Khademi F (2017) Systematic review and meta-analysis of imipenem-resistant Pseudomonas aeruginosa prevalence in Iran. Germs 7(2):86-97

3. Moradali MF, Ghods S, Rehm BH (2017) Pseudomonas aeruginosa lifestyle: a paradigm for adaptation, survival, and persistence. Front Cell Infect Microbiol 7:39

4. Ignak S, Nakipoglu Y, Gurler B (2017) Frequency of antiseptic resistance genes in clinical staphycocci and enterococci isolates in Turkey. Antimicrob Resist Infect Control 6(1):1-7

5. Vásquez-Giraldo DF, Libreros-Zúñiga GA, Crespo-Ortiz MD (2017) Effects of biocide exposure on P. aeruginosa, E. coli and $A$. baumannii complex isolates from hospital and household environments. Infectio 21(4): $243-50$

6. Wesgate R, Grasha P, Maillard J-Y (2016) Use of a predictive protocol to measure the antimicrobial resistance risks associated with biocidal product usage. Am J Infect Control 44(4):458-464

7. Ortega-Morente E, Fernández-Fuentes MA, Grande-Burgos MJ, Abriouel H, Pérez-Pulido R, Gálvez A (2013) Biocide tolerance in bacteria. Int J Food Microbiol 162(1):13-25

8. Murray PR, Rosenthal KS, Pfaller MA (2015) Medical microbiology, 8th edn. Elsevier Health Sciences, UK, pp 272-277

9. Bridier A, Dubois-Brissonnet F, Greub G, Thomas V, Briandet R (2011) Dynamics of the action of biocides in Pseudomonas aeruginosa biofilms. Antimicrob Agents Chemother 55(6):2648-2654

10. Mima T, Joshi S, Gomez-Escalada M, Schweizer HP (2007) Identification and characterization of TriABC-OpmH, a triclosan efflux pump of Pseudomonas aeruginosa requiring two membrane fusion proteins. J Bacteriol 189(21):7600-7609

11. Vikram A, Bomberger JM, Bibby KJ (2015) Efflux as a glutaraldehyde resistance mechanism in Pseudomonas fluorescens and Pseudomonas aeruginosa biofilms. Antimicrob Agents Chemother 59(6):3433-3440

12. Chuanchuen R, Beinlich K, Hoang TT, Becher A, Karkhoff-Schweizer RR, Schweizer HP (2001) Cross-resistance between triclosan and antibiotics in Pseudomonas aeruginosa is mediated by multidrug efflux pumps: exposure of a susceptible mutant strain to triclosan selects nfxB mutants overexpressing MexCD-OprJ. Antimicrob Agents Chemother 45(2):428-432

13. Subedi D, Vijay AK, Willcox M (2018) Study of disinfectant resistance genes in ocular isolates of Pseudomonas aeruginosa. Antibiotics 7(4):88

14. CLSI (2018) Performance Standards for Antimicrobial Susceptibility Testing; Twenty-Eighth Informational Supplement. CLSI Document M100. Clinical and Laboratory Standards Institute, Wayne

15. Bazghandi SA, Safarirad S, Arzanlou M, Peeri-Dogaheh H, AliMohammadi H, Khademi F (2021) Prevalence of multidrug-resistant Pseudomonas aeruginosa strains in Ardabil. J Ardabil Univ Med Sci 20(2):280-286

16. Rizzotti L, Rossi F, Torriani S (2016) Biocide and antibiotic resistance of Enterococcus faecalis and Enterococcus faecium isolated from the swine meat chain. Food Microbiol 60:160-164 
17. Chapman JS (2003) Biocide resistance mechanisms. Int Biodeterior Biodegradation 51(2):133-138

18. Romão C, Miranda CA, Silva J, Clementino MM, de Filippis I, Asensi M (2011) Presence of qacE 1 gene and susceptibility to a hospital biocide in clinical isolates of Pseudomonas aeruginosa resistant to antibiotics. Curr Microbiol 63(1):16-21

19. Zhu L, Lin J, Ma J, Cronan JE, Wang H (2010) Triclosan resistance of Pseudomonas aeruginosa PAO1 is due to FabV, a triclosanresistant enoyl-acyl carrier protein reductase. Antimicrob Agents Chemother 54(2):689-698

20. Heath RJ, Rock CO (2000) A triclosan-resistant bacterial enzyme. Nature 406(6792):145-146

21. Huang YH, Lin JS, Ma JC, Wang HH (2016) Functional characterization of triclosan-resistant enoyl-acyl-carrier protein reductase (FabV) in Pseudomonas aeruginosa. Front Microbiol 7: 1903

22. Thomas L, Maillard JY, Lambert RJ, Russell AD (2000) Development of resistance to chlorhexidine diacetate in Pseudomonas aeruginosa and the effect of a'residual'concentration. J Hosp Infect 46(4):297-303

23. Hassan KA, Liu Q, Henderson PJ, Paulsen IT (2015) Homologs of the Acinetobacter baumannii Acel transporter represent a new family of bacterial multidrug efflux systems. MBio 6(1):e01982-e01914

24. Mendes ET, Ranzani OT, Marchi AP, da Silva MT, Amigo Filho JU, Alves T, Guimarães T, Levin AS, Costa SF (2016) Chlorhexidine bathing for the prevention of colonization and infection with multidrug-resistant microorganisms in a hematopoietic stem cell transplantation unit over a 9-year period: Impact on chlorhexidine susceptibility. Medicine 95(46):1-8

25. Vijayakumar R, Sandle T, Al-Aboody MS, Alfonaisan MK, Alturaiki W, Mickymaray S, Premanathan M, Alsagaby SA (2018) Distribution of biocide resistant genes and biocides susceptibility in multidrug-resistant Klebsiella pneumoniae, Pseudomonas aeruginosa and Acinetobacter baumannii-A first report from the Kingdom of Saudi Arabia. J Infect Public Health 11(6):812-816

26. Kücken D, Feucht $\mathrm{HH}$, Kaulfers PM (2000) Association of qacE and qacE 1 with multiple resistance to antibiotics and antiseptics in clinical isolates of Gram-negative bacteria. FEMS Microbiol Lett 183(1):95-98

27. Helal ZH, Khan MI (2015) QacE and QacE 1 Genes and Their Correlation to Antibiotics and Biocides Resistance Pseudomonas aeruginosa. Am J Biomed Sci 7(2): 52-62

28. Mahzounieh M, Khoshnood S, Ebrahimi A, Habibian S, Yaghoubian M (2014) Detection of antiseptic-resistance genes in Pseudomonas and Acinetobacter spp. isolated from burn patients. Jundishapur J Nat Pharm Prod 9(2):e15402

29. McDonnell G, Russell AD (1999) Antiseptics and disinfectants: activity, action, and resistance. Clin Microbiol Rev 12(1):147-179 